\title{
O ENSINO COM GÊNEROS TEXTUAIS E O LETRAMENTO EM LÍNGUA MATERNA NO PROGRAMA DE ACELERAÇÃO DA APRENDIZAGEM ASAS DA FLORESTANIA - ACRE
}

\author{
José Júlio César do Nascimento Araújo ${ }^{1}$ \\ ${ }^{1}$ Professor de Língua Portuguesa na rede estadual de ensino do Acre e Amazonas; Mestre em Desenvolvimento Regional (UFAC). e- \\ mail: amadeus13julio@gmail.com
}

\section{RESUMO}

Este artigo analisa como é realizado o ensino de produção textual em sala de aula no Programa de aceleração Asas da Florestania, em escolas públicas rurais de Cruzeiro do Sul- Acre. O foco central está voltado para a relação entre cognição, construção de conceitos e estratégias de representação da informação por meio de gêneros discursivos. Entende-se por gêneros do discurso, nesta proposta, as superestruturas. $\mathrm{O}$ trabalho foi desenvolvido com base na metodologia qualitativa e tem como arcabouço teórico, principalmente, os postulados de VanDijk, (2004), Lopes- Rossi (2002) e Fairclough (2001). Buscase ampliar a questão: será que quando os professores enunciam as designações gêneros do discurso ou gêneros textuais ou tipos textuais, estão significando o mesmo objeto teórico? Desta forma, é necessário, antes de tudo, compreender sobre o que se está abordando nas aulas de Língua Portuguesa no programa Asas da Florestania, e quais as peculiaridades abrangentes em cada diferente abordagem. Os textos foram coletados de atividades realizadas em sala pelas professoras do Programa Asas da Florestania em Cruzeiro do Sul/AC. Na análise dos textos e dos resultados, trabalhei para verificar de que a maneira as professoras orientam as práticas discursivas de seus alunos em relação aos textos multimodais e se esse trabalho contribui para a construção crítica do discurso do aluno e, ainda, quais são as orientações quanto às múltiplas funções e os significados dos Letramentos, subjacentes às práticas discursivas utilizadas pelas professoras. Procura-se, enfim, compreender como são trabalhados os gêneros discursivos na sala de aula em uma comunidade amazônica.

Palavras- chave: Gêneros textuais, letramento, Asas da Florestania, Ensino de Língua Portuguesa.

\section{TEACHING WITH TEXT GENRES AND LITERACY IN NATIVE LANGUAGE IN THE ACCELERATED LEARNING PROGRAM ASAS DA FLORESTANIA - ACRE}

\begin{abstract}
This article shows how you performed the teaching of writing in the classroom in the Wings Program Florestania acceleration in rural public schools of the Southern Cross-Acre. The central focus is directed at the relationship between cognition, building concepts and strategies of representation of information through genres. It is understood by speech genres, in this proposal, the superstructures. The work was developed based on qualitative methodology and its theoretical framework, especially the postulates VanDijk, (2004), Lopes-Rossi (2002) and Fairclough (2001). They want to expand the question: is that when teachers set out the names of discourse genres or genre or text types, are meaning the same theoretical object? Thus, it is necessary first of all, understand what you are addressing in Portuguese classes in the program Wings of Florestania, and what peculiarities in each different comprehensive approach. The texts were collected from classroom activities by teachers Florestania Wings of the Program on Southern Cross / AC. In analyzing the texts and the results have worked to see that the way the teachers guide the discursive practices of their students in relation to multimodal texts and this work contributes to building a critical discourse of the student, and also what are the guidelines regarding the many functions and meanings of Literacy, underlying the discursive practices used by teachers. Wanted, finally, to understand how the genres are worked in the classroom in an Amazonian community.
\end{abstract}

Keywords: Genre, literacy, Wings of Florestania, Portuguese Language Teaching 


\section{INTRODUÇÃO}

Este texto focalizará o ensino de estratégias de produção textual em sala de aula no Programa de aceleração Asas da Florestania, em escolas públicas rurais de Cruzeiro do SulAcre. O foco central está voltado para a relação entre cognição, construção de conceitos e estratégias de representação da informação por meio de gêneros discursivos.

Entende-se por gêneros do discurso, nesta proposta, as superestruturas. Para Van Dijk (2004), as superestruturas são o conjunto de conhecimentos sobre diversos tipos de textos e as correlação entre eles, as estruturas globais que se assemelham a um esquema e determinam a forma global do texto, definida por uma sintaxe própria a cada tipo textual.

No entanto, importa-nos, neste artigo, identificar quais saberes conceituais subsidiam as práticas dos professores no ensino do texto e o reflexo de suas práticas sobre a aprendizagem dos alunos. Pois, como compreende Fairclough (2001, p. 35-36):

\begin{abstract}
A conexão entre o texto e a prática social é vista como mediada pela prática discursiva: de um lado, os processos de produção e interpretação são formados pela natureza da prática social, ajudando também a formá-la e, por outro lado, o processo de produção forma (e deixa vestígios) no texto, e o processo interpretativo opera sobre 'pistas' no texto.
\end{abstract}

Buscaremos, assim, refazer e ampliar a questão: será que, quando os professores enunciam as designações gêneros do discurso ou gêneros textuais ou tipos textuais, estamos significando o mesmo objeto teórico? Desta forma, é necessário, antes de tudo, compreender sobre o que se está abordando nas aulas de Língua Portuguesa no Programa Asas da Florestania, e quais as peculiaridades abrangentes em cada diferente abordagem. Busca-se, enfim, compreender como são trabalhados os gêneros discursivos na sala de aula em uma comunidade amazônica.

\section{O ensino de gêneros textuais na escola}

Com o aprofundamento do processo de reflexão a respeito do ensino de língua materna no Brasil, a partir do lançamento dos PCNs de Língua Portuguesa em 1999, cujo eixo teórico centra-se na abordagem do texto enquanto objeto de ensino, numa perspectiva dos gêneros, tem-se percebido a ênfase dada aos estudos sobre texto e os desdobramentos metodológicos da sua aplicação no ensino da língua materna. (LOPES ROSSI, 2002)

Ao final da década de 90 , multiplicam-se os estudos sobre o texto, especialmente em torno do conceito de gêneros discursivos popularizados pelos PCNs, com base nas teorias de Mickail Bakhtin (1997). Mussalim e Bentes (2001) mostram que os vários estudos sobre o texto passaram a assumir outro caminho para a constituição de outro campo que procura ir além da frase, reintroduzindo a situação de comunicação, em oposição ao campo construído pela Linguística Estrutural.

A proposta dos PCN postula o texto como unidade funcional e intersubjetivamente construída. Por isso, a necessidade de se estabelecer critérios para seleção de diferentes tipos de texto em circulação social, como forma de se garantir uma progressão curricular que os contemple ao longo das séries escolares.

Dentre as abordagens compreensivas sobre as metodologias atuais de ensino do texto, destaca-se Van Dijk $(2004,2008)$. Suas teorias decorrem da compreensão sobre os tipos textuais e dos gêneros como superestruturas. Van Dijk (2004) considera o texto-produto, como unidade linguística mais elevada, a partir da qual seria 
possível chegar a unidades menores a serem classificadas.

Van Dijk (2008) propõe o estudo das macroestruturas textuais (relacionadas ao significado ou coerência global do texto); das microestruturas (cada um dos enunciados locais que contribuem para o significado global) e das superestruturas ou esquemas textuais e, portanto, a questão das tipologias textuais, estudadas pelo viés essencialmente cognitivo.

Van Dijk (2004) esclarece que os tipos de textos se diferenciam não apenas por suas diferentes funções comunicativas, por seus diferentes tipos de conteúdos e por suas diferentes funções sociais, mas também possuem diferentes tipos de construção. Dessa forma, os textos não apenas possuem uma estrutura semântica global, possuem também uma estrutura esquemática global, chamada de superestrutura. Uma estrutura esquemática consiste de uma série de categorias hierarquicamente ordenadas, muito similares às categorias de um esquema narrativo. Estas categorias possuem funções específicas relacionadas às respectivas macroproposições de um texto. Uma superestrutura esquemática é meramente uma estrutura formal, muito similar à sintaxe de uma oração. Ela é preenchida com o conteúdo da macroestrutura semântica.

A ideia de superestrutura de Van Dijk (2004) surge como um elemento necessário ao processamento da linguagem. Partindo do estudo das gramáticas textuais, o autor chega ao tipo de texto como um componente central do modelo de compreensão e produção textual.

A superestrutura como componente do modelo de processamento é um recurso descendente que 0 sujeito instancia para conformar as proposições processadas. Confere a forma que elas devem adquirir em conjunto para preencher as expectativas de determinada situação comunicativa, em determinado contexto cultural. Esse processo se desencadeia, tanto na recepção, quanto na produção, durante os tratamentos micro e macroestruturais. Nas palavras de Van Dijk (2003, p. 54), "as superestruturas são esquemas para as formas convencionais dos textos; sendo que 0 conhecimento dessas formas facilita a geração, a recordação e a produção de macroestruturas". Nem todos os tipos de texto têm tais formas convencionais, mas quando elas existem parece desempenharem um papel considerável no processamento da compreensão leitora.

A seguir, apresentamos como 0 Programa Asas da Florestania tem realizado o ensino da produção textual e compreendido o texto como unidade de ensino. Na perspectiva de Rojo (2000), e Lopes-Rossi (2002) dentre outros que vêm tentando delinear propostas metodológicas para o ensino de língua materna, destacando em especial as que apresentam um ensino baseado em gêneros do discurso, todos esses estudos mostraram a necessidade do ensino da Língua Portuguesa por meio da Linguística Textual.

\section{A metodologia do Programa Asas da} Florestania: entre o método e o observado

Maingueneau (2001) tem colocado que a escola deve trabalhar diversos gêneros no ambiente escolar. Por outro lado, Lopes - Rossi (2002, p. 20) tem destacado que as condições de produção de redação são consideradas inadequadas, porque trabalham com a artificialidade da redação e dos temas propostos, descaracterizam o aluno como sujeito no uso da linguagem (ele procura reproduzir o discurso da escola) e, além disso, faltam objetivos de escrita, falta um real leitor e acompanhamento do professor nas várias etapas de elaboração do texto.

O que se observa é que o desafio imposto por Maingueneau (2001) não tem sido 
encarado com a dimensão que este impõe e, por outro lado, o que se vê são reproduções de cenários já descritos por Lopes-Rossi (2002, p. 20); o ensino de língua materna não tem trabalhado os diversos gêneros no ambiente escolar. Por isso, nas escolas tanto públicas como privadas, ainda observamos práticas do ensino de Língua Portuguesa pautadas no ensino da gramática tradicional, com frases isoladas ou com exemplos retirados dos clássicos. Em outras práticas, vemos professores usando o texto como pretexto para o ensino de gramática, num esforço de localizar classes de palavras.

Minha trajetória, como professor de língua portuguesa nas escolas do Acre e do Amazonas, na zona urbana e rural, me nos levou a perceber que os professores ainda sustentavam práticas e metodologias de ensino da Língua Portuguesa que já não eram condizentes com a atual necessidade de letramento dos alunos. Tive, então, a oportunidade de conhecer, de perto, o ensino dentro do Programa Asas da Florestania na Escola Magia do Saber, BR 364, Comunidade Liberdade.

O Programa Asas da Florestania envolve um conjunto de ações da Fundação Roberto Marinho e da Secretaria de Educação do Estado do Acre, que procura proporcionar escolarização em comunidades rurais de difícil acesso. O Programa foi iniciado em 2003 em Xapuri, seguindo a metodologia do Projeto Seringueiro (1983). Porém, adotou, depois da parceria, com a Fundação Roberto Marinho, parte da metodologia do Telecurso $2000^{1}$. A finalidade do Programa é levar o ensino fundamental (de $5^{\mathrm{a}}$ a $8^{\mathrm{a}}$ séries) e ensino médio para alunos de comunidades isoladas. Hoje, o Programa funciona em 161 comunidades de 14 municípios atendidos.

\footnotetext{
${ }^{1}$ Fala de Francisca das Chagas Souza da Silva, a Professora Chiquinha, gerente pedagógica de Ensino Rural da Secretaria de Estado da Educação na entrevista "Programa Asas da Florestania" leva educação ao interior do Acre de 19 de fevereiro de 2008. Fonte: www.agencia.ac.gov.br
}

A metodologia do Telecurso2000, segundo a Fundação Roberto Marinho, utiliza os conhecimentos que o aluno já possui para incorporar novos e também habilidades que podem ser imediatamente transferidas para 0 contexto da vida social e da sua formação pessoal. Desse modo, é possível desenvolver os conteúdos do Programa do curso bem como as habilidades básicas, as questões de cidadania e a capacidade empreendedora de cada um. Como a metodologia promove a diminuição no tempo de aprendizado, é possível completar as séries (da $5^{\mathrm{a}}$ a $8^{\mathrm{a}}$ ) do ensino fundamental ou das séries do ensino médio, em um ano e seis meses, ao invés de em quatro anos.

O curso é realizado obedecendo a antigos modelos de se fazer educação. Nas paredes da escola, há cartazes escritos a mão, reafirmando a proposta pedagógica do Asas da Florestania, que é, em sua essência, a de suprir uma antiga e dramática lacuna na educação rural: a sequência do ensino que terminava, nas comunidades rurais, na $4^{\mathrm{a}}$ série.

Porém, na práxis do Asas da Florestania, o que se vê é um curso "aligeirado" sem tempo e espaço para as reflexões linguísticas. Os professores não dispõem de recursos tecnológicos e o caráter multidisciplinar de sua formação impõe dificuldades quanto ao que se ensina e como se ensina. O que queremos dimensionar é que, para o Asas da Florestania, o professor pode ter formação nas mais diversas áreas do conhecimento, desde que seja no nível de licenciatura.

Ora, ensinar produção de texto com finalidade de letramento dos discentes exige dos professores habilidades e competências específicas. A metodologia do Programa para o ensino de Língua Portuguesa segue um percurso já criticado por Koch (1997), para quem a escola deve abordar o ensino da produção textual, tendo por objetivo o seu domínio. No Programa, 
empregam-se sequências estereotipadas no decorrer do curso, em geral "descrição, narração, dissertação", às quais, por vezes, se acrescentam outros tipos, como o resumo.

\section{Análise dos textos coletados com os alunos} do Asas da Florestania

O estudo da linguagem deve assumir posturas que o validem, tais como precisar as condições de produção e de acepção do texto, identificando quem escreve, para quem escreve, com que finalidade, em que situação de fala e escrita o texto foi produzido, quais as condicionantes das variações linguísticas ou mudanças dos termos.

Revisando a literatura de Van Dijk (2004) para o ensino de Língua Portuguesa, definimos como uma das etapas desta pesquisa a análise dos textos coletados no ambiente escolar. O trabalho foi desenvolvido com base na metodologia qualitativa e tem como arcabouço teórico, principalmente, os postulados de Van Dijk, (2004), Lopes - Rossi (2002) e Fairclough (2001).

Os textos foram coletados de atividades realizadas em sala pelas professoras do Programa Asas da Florestania em Cruzeiro do Sul/AC. Na análise dos textos e dos resultados, trabalhei para verificar de que a maneira as professoras orientam as práticas discursivas de seus alunos em relação aos textos multimodais e se esse trabalho contribui para a construção crítica do discurso do aluno e, ainda, quais são as orientações quanto às múltiplas funções e os significados dos Letramentos, subjacentes às práticas discursivas utilizadas pelas professoras.

Nesse sentido, Fairclough (1999) propõe um arcabouço metodológico que pressupõe dois tipos de análise: "a análise da conjuntura" - é a especificação da rede de práticas da qual o discurso faz parte, ou seja, é a configuração de práticas da qual o discurso em análise é parte. "A análise da prática particular" - ênfase para os momentos da prática em foco no discurso, para as relações entre o discurso e os outros momentos e a "análise do discurso" - orientada para a "estrutura" (a relação das instâncias discursivas analisadas juntamente com as ordens de discurso e sua recorrência a gêneros, discursos e vozes) e para a "interação" (análise linguística de recursos utilizados no texto e sua relação com a prática social). Os textos coletados mostram que havia, por parte dos professores, uma consciência da necessidade de trabalhar temas diferenciados; porém, as noções de gênero e tipos textuais ainda não se encontravam devidamente delineados. No primeiro texto a ser analisado temos uma narração. A ideia central da atividade era imaginar Pedro Álvares Cabral chegando ao Brasil no ano 2000 e o que sua expedição pensaria daquele povo civilizado.

FIGURA1 - Introdução de uma narração (aluno 8ªno)

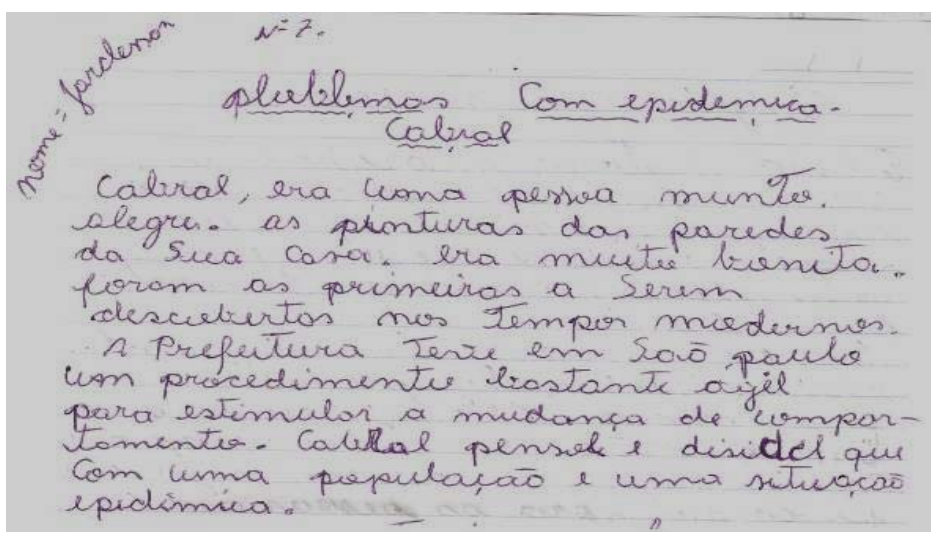

Fonte: Pesquisa de Campo, 2010.

Como se pode perceber, apresentamos apenas o início do texto, dado o caráter desta comunicação. Porém, observamos que o aluno não conseguiu introduzir seu texto. Iniciando pelo título, observa-se que este contém problemas linguísticos em relação à língua culta. Deixando a farta análise da gramática tradicional de lado, partamos para um olhar sobre o texto, a partir da Linguística Textual. Bonini (2005) destaca que a 
narração não contempla o escopo social dos textos pelo alto grau de abstração que impõe. No texto do aluno, não há uma coerência lógica, sentido e organização de ideias, mostrando que o aluno não compreendeu o objetivo do texto e também não teve acompanhamento, por parte do professor, durante a produção do mesmo.

No segundo texto, temos uma

propaganda. Nesta, o professor, ao propor a atividade de propaganda, a partir do solicitado em um livro didático, pediu que os alunos escolhessem um tema para fazer uma propaganda. Foi explicado aos alunos como era a estrutura do texto persuasivo e seu objetivo. Vejamos uma dessas propagandas:

FIGURA 2 - Propaganda ${ }^{\text {( }}$ aluno do $1^{\circ}$ ano do Ensino Médio)

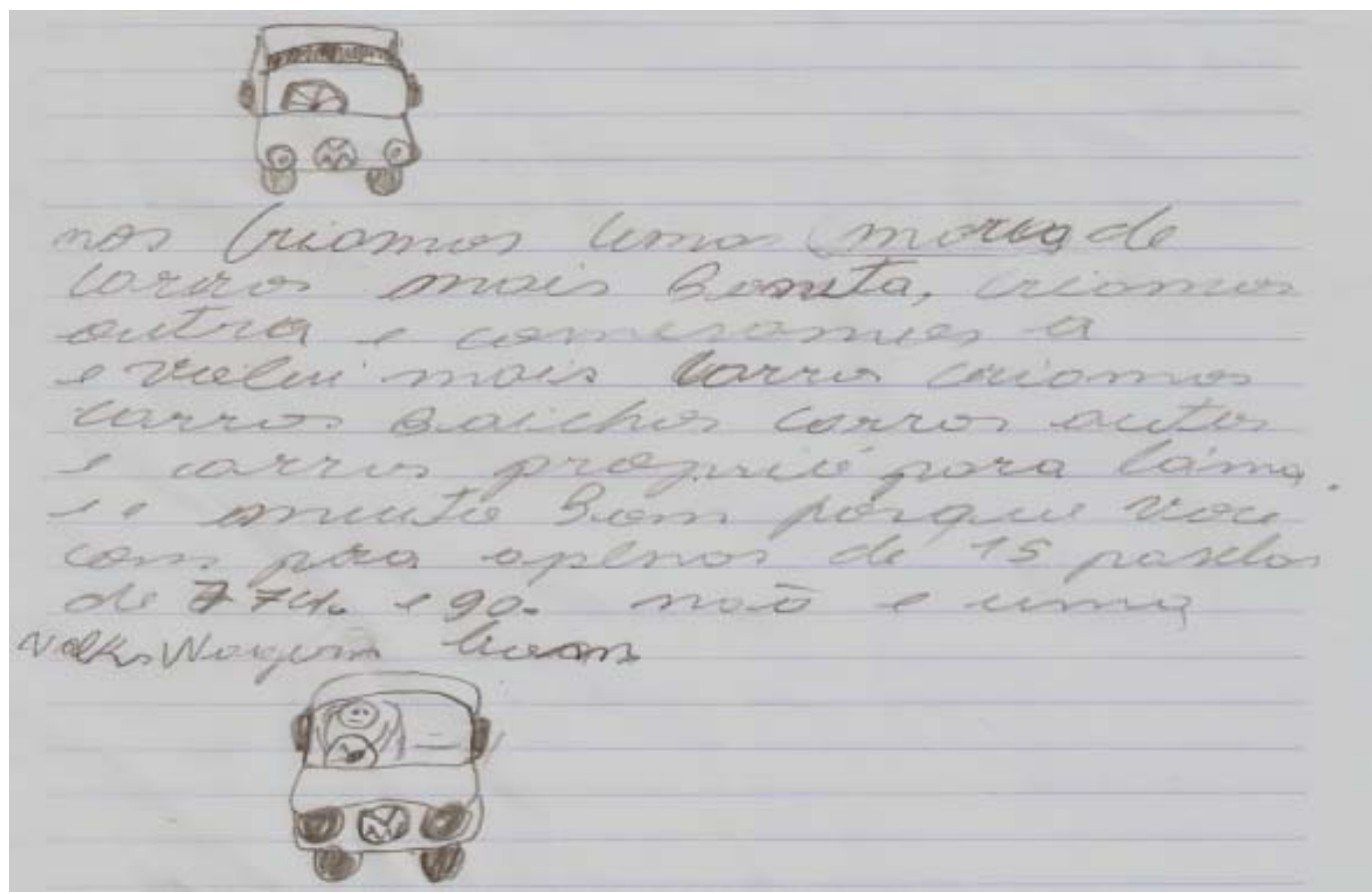

Fonte: Pesquisa de Campo, 2010

\section{Transcrição literal do texto}

nos criamos uma marca de carros mais bonita,criamos outra e comesamos a evolui mais carros criamos carros baichos carros autos e carros proprió para lama.e muito bomporque voce com pra apenas de 15 paselas de 774 e 90 . não e volkswagem bom

Como se observa mesmo no ensino médio há dificuldades de organização do texto. Há sérios problemas de ortografia que precisam ser vencidos e, por outro lado, após a primeira frase, o texto se torna confuso. Há também ausência de elementos coesivos, porém cabe destacar a consciência do aluno sobre a importância da imagem no texto.

Para o enriquecimento da multiplicidade de Letramentos (VIEIRA, 2003) o ensino de
Língua Portuguesa não pode prescindir da análise imagética, pois há muitos eventos de Letramento que apresentam não só linguagem escrita e falada, mas também diferentes sistemas semióticos. Desta feita os texto produzidos na escola, as vezes usam abordagens multimodais. O que presenciamos nessa atividade é o uso da propaganda seguida de uma imagem criada pelo próprio aluno, o que demonstra que embora haja pouca consciência gramatical do discurso e 
também da organização textual, há um nível de letramento.

No terceiro texto, que analisaremos a seguir, iremos notar que o professor realizou a correção, tendo em vista que era um texto para ser avaliado com notas somativas para o bimestre escolar. Vejamos o texto:

FIGURA 3 - Texto da aluna ( $9^{\circ}$ ano) corrigido pelo professor

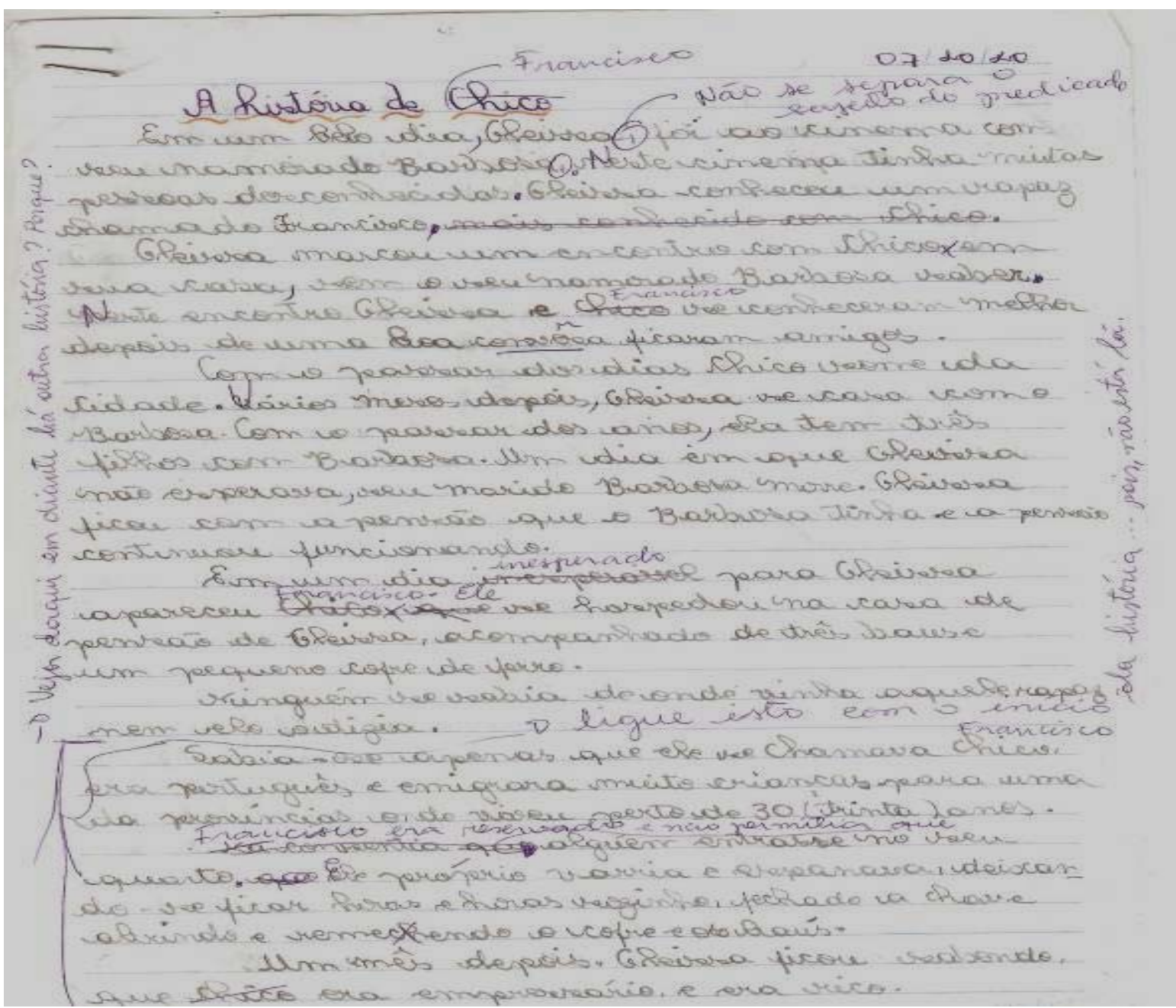

Fonte: Pesquisa de Campo, 2010.

As correções do professor no texto estão voltadas para a organização gramatical do texto. O trabalho proposto é de reescrita do conto Vovó Andrade, de Artur Azevedo. O tipo de acompanhamento proposto pelo professor, embora pudesse ser melhor, ajudou o aluno a melhorar significativamente seu texto, ao fazê-lo refletir como poderia melhorá-lo, levando-o a perceber que seu texto estava sem sentido em algumas partes.

\section{CONCLUSÕES}

O fracasso das atividades de produção de texto depende da ausência de qualidade do ensino com texto, pelo texto e sobre o texto. Quando o professor oportuniza situações de trabalho com gêneros que sejam eficazes há melhoria na qualidade do escrito.

No Programa Asas da Florestania, não há tempo espaço para o ensino com gêneros, tendo em vista a urgência de formação em todas as disciplinas da série ou ciclo. Esses "programas 
aligeirados", mesmo que seja inegável seu caráter social, político e educacional, tentam apenas resolver a distorção série-idade, ou oferecer oportunidade de formação (entenda-se de certificação) aos alunos que se encontram distante dos grandes centros.

Tal faceta cria um paradoxo para a finalidade real da educação: "educação é uma forma de intervenção no mundo" (FREIRE, 2000, p. 110). Portanto, se não há possibilidade de letramento no aprendizado de Língua Materna, a atividade de ensino torna-se neutra, uma vez que impossibilita o aluno da irrecusável prática de interagir, dialogar, comunicar e produzir compreensão do que é comunicado e de comunicar-se eficientemente em todos os ambientes sociais possíveis, lendo o mundo à sua volta.

\section{REFERÊNCIAS}

BAKHTIN, M. Estética da criação verbal. São Paulo: Martins Fontes, 1997.

BONINI, A. (Orgs.). Gêneros: Teorias, métodos e debates. São Paulo: Parábola, 2005.

BRASIL. Ministério da Educação. Secretaria de Educação Fundamental. Parâmetros Curriculares Nacionais. vol.2. Brasília, SEF/MEC, 1998.

DIONÍSIO, A. P.; MACHADO, A. R.; BEZERRA, $M$. A. (Orgs.). Gêneros textuais e ensino. Rio de Janeiro: Lucerna, 2002.

FAIRCLOUGH, N. Discurso e mudança social. Brasília: UnB, 2001.

FREIRE, P. Pedagogia da Autonomia: saberes necessários à pratica docente. 16.ed. São Paulo: Paz e Terra, 2000.

KOCH, I.G.V. O Texto e a Construção dos Sentidos. São Paulo: Contexto, 1997.

LOPES-ROSSI, M. A. G. A produção de texto escrito com base em gêneros discursivos. In: SILVA, E. R. da (Org.). Texto e ensino. Taubaté, SP: Cabral, 2002.

MAINGUENEAU, D. Elementos de lingüística para o texto literário. São Paulo: Martins Fontes, 2001.
MUSSALIM, F.; BENTES, A. C. (orgs.). Introdução à lingüística: domínios e fronteiras. São Paulo: Cortez Editora, 2001.

ROJO, R. (org.). A prática de linguagem em sala de aula. São Paulo: Educ. Campinas: Mercado de Letras, 2000.

VAN DIJK, T. A. La ciencia del texto: un enfoque interdisciplinario. Barcelona e Buenos Aires: Ediciones Paidós, 2003.

VAN DIJK, T. A. Cognição, discurso e interação. São Paulo: Contexto, 2004.

VAN DIJK, T. A. Discurso e Poder. São Paulo: Contexto, 2008.

VIEIRA, J. A. Práticas sociais de letramento e ensino crítico em língua portuguesa. In SILVA, D. E. G.; VIEIRA, J. A. Práticas de Análise do Discurso. Brasília: Plano, 2003. 